\title{
Processos de inclusão de crianças e jovens com e sem deficiência em práticas artísticas.
}

\author{
SABRINA LINS BATISTA \\ DENISE ANDRADE DE FREITAS MARTINS \\ PÂMELA SILVA ROCHA
}

Sabrina Lins Batista é Graduanda no curso de Psicologia (Bacharelado) na Universidade do Estado de Minas Gerais, unidade Ituiutaba (UEMG). Estudante pesquisadora bolsista PAPq/UEMG 2019 e estudante voluntária em projetos de extensão desde 2018, com experiência na área de Psicologia infantil e adolescente, pessoas com deficiência, desenvolvimento humano, práticas artísticas e musicais.

Afiliação: Universidade do Estado de Minas Gerais, Ituiutaba, Minas Gerais.

Lattes: http://lattes.cnpq.br/2323087251295173

Orcid: https://orcid.org/0000-0002-4095-7478

Denise Andrade de Freitas Martins possui pós-doutorado em Música pela Universidade Federal de Minas Gerais (2021). Doutora em Educação pela Universidade Federal de São Carlos (2015), Doutorado Sanduíche no Exterior (PDSE), Moçambique (2013), como bolsista CAPES (Coordenação de Aperfeiçoamento de Pessoal de Nível Superior). Mestre em Educação Musical, Conservatório Brasileiro de Música do Rio de Janeiro-Centro Universitário (2000). Licenciatura Plena em Música-Piano pela Faculdade Mozarteum de São Paulo (1985); Licenciatura Curta em Piano pela Universidade Federal de Uberlândia (1982); Bacharel em Piano pela Faculdade Mozarteum de São Paulo (1986); Licenciatura em Pedagogia (UNIUBE/MG, 2016). Docente da Universidade do Estado de Minas Gerais (UEMG, unidade Ituiutaba). Pesquisadora na linha de práticas sociais e processos educativos e música contemporânea brasileira.

Afiliação: Universidade do Estado de Minas Gerais, Ituiutaba, Minas Gerais.

Lattes: http://lattes.cnpq.br/7018352729022664

Orcid: https://orcid.org/0000-0003-1164-498X

Pâmela Silva Rocha é Graduanda no curso de Psicologia (Bacharelado) na Universidade do Estado de Minas Gerais, unidade Ituiutaba (UEMG). Estudante pesquisadora e integrante do grupo de pesquisa Núcleo de Estudos Interdisciplinares (NESI), cadastrado e reconhecido pelo Conselho Nacional de Pesquisa (CNPq), nas linhas de pesquisa em Arte, Educação e Psicologia.

Afiliação: Universidade do Estado de Minas Gerais, Ituiutaba, Minas Gerais.

Lattes: http://lattes.cnpq.br/8316763233773960

Orcid: https://orcid.org/0000-0002-1372-8901 


\section{- RESUMO}

O presente artigo é fruto do projeto de pesquisa desenvolvido em 2019 na Universidade do Estado de Minas Gerais (UEMG), unidade Ituiutaba, denominado "Práticas artísticas e musicais com crianças e jovens com deficiência: inclusão ou interação?". Os objetivos foram identificar se práticas artísticas favorecem a interação entre crianças e jovens com e sem deficiência, da escola de educação básica e da Associação de Pais e Amigos dos Excepcionais (APAE), no que se refere aos processos de inclusão e reconhecer os processos educativos decorrentes dessa convivência. A metodologia de intervenção constou de encontros semanais registrados em diários de campo, principal instrumento de coleta de dados, com posterior análise ideográfica e nomotética, além de fotos e filmagens. A fundamentação teórica se sustentou principalmente nos princípios pedagógicos de Paulo Freire (2005) e nos conceitos de desenvolvimento humano de Vygotsky (1998, 1999, 2000) e de Papalia e Feldman (2013). Os resultados apontaram que práticas artísticas desenvolvidas com pessoas com e sem deficiência são capazes de potencializar novas habilidades, conhecimentos e promover uma melhor convivência, mesmo em face das dificuldades enfrentadas no dia a dia dos encontros. Esperamos que esse trabalho possibilite reflexões acerca da temática e que possa contribuir com os estudos na área, suscitando a realização de novas pesquisas e mostrando-se como importante atividade no processo de formação de estudantes em nível de graduação.

\section{PALAVRAS-CHAVE}

Práticas artísticas, inclusão, crianças e jovens, deficiência.

\section{- ABSTRACT}

The present paper is the result of the research project developed in 2019 at the State University of Minas Gerais (UEMG), Ituiutaba campus, named "Musical and Artistic Practices with disabled children and youngsters; inclusion or interaction?". The objectives were to identify if artistic practices favour interaction among disabled children and youngsters with the ones who are not disabled at basic education schools and the Association for Parents and Friends of the Disabled (APAE), regarding the inclusion processes and acknowledging the educational processes derived from this coexistence. The intervention methodology was performed with weekly meetings registered in field journals, main tool for data collection with later ideographic and nomothetic analysis, besides photographs and video footages. The theoretical reference was mainly supported by the pedagogical principles of Paulo Freire (2005) and on the human development concepts of Vygotsky $(1998,1999,2000)$ and Papalia and Feldman (2013). Results highlighted that artistic practices developed with disabled and non-disabled people are capable of enabling new skills, knowledge and promoting a better coexistence, even with the difficulties faced daily during the meetings. It is hoped that this study enables reflections upon the theme and may contribute with other studies in the area, provoking the carrying out of new research and showing itself as an important activity in the graduation process of college students.

\section{KEYWORDS}

Artistic practices, inclusion, children and youngsters, disabilities. 


\section{Pensando conceitos, ideias e entendimentos...}

A arte é uma atividade social realizada entre os seres humanos e os efeitos que dela emanam, segundo Vygotsky (1999), não traduzem a ideia de que a realização humana, mesmo vista isoladamente, seja um processo individual. Quando a catarse ocorre e provoca as comoções da alma, o efeito gerado é social, de onde entendemos que crianças e jovens envolvidos na realização e desenvolvimento de práticas artísticas podem experimentar tanto satisfações como contrariedades e frustrações, gerando liberdade de percepções e emoções.

Em Papalia e Feldman (2013), o comportamento pró-social é um comportamento de coletividade, iniciando-se em geral na terceira infância (por volta dos 7 anos de idade). A partir dessa faixa etária é que as crianças e jovens começam a ter consciência acerca das emoções que as afetam, tendendo a agir de maneira mais empática, lidando com a autoestima e dando início a um discernimento sobre o processo de socialização. Assim, no que se refere ao desenvolvimento humano, entendemos ser de extrema importância a realização de práticas artísticas por e com crianças e jovens com e sem deficiência na terceira infância, ao que Vygotsky (2000) denominou de processos de resposta por "mediação", como meio de promover a interação entre as crianças e jovens.

Em geral, práticas artísticas desenvolvidas com crianças e jovens com e sem deficiência, segundo Vygotsky (2000), apresentam no processo de mediação uma relação instrumental, na qual geralmente um adulto é o intermediador para a promoção de aprendizagem e desenvolvimento humano da criança/jovem. A consequência da ação possível é a resposta do adulto, de onde compreendemos que, quando se utiliza a arte em contextos de práticas artísticas como instrumento mediador, as crianças e jovens com e sem deficiência apresentam não só as habilidades artísticas em suas potencialidades, como também, desenvolvimento emocional e cognitivo. Para Papalia e Feldman (2013), crianças a partir da terceira fase de desenvolvimento começam a aprender sentimentos, como raiva, tristeza, alegria e, ainda mais, comportam-se de acordo com a situação. Desse modo, a arte pode auxiliar no desenvolvimento emocional.

Para Pederiva e Tristão (2006), a música em particular contribui de diversas formas para o desenvolvimento cognitivo das pessoas, além de estimular a associação de diversas funções psicossociais como a comunicação e o desenvolvimento da linguagem compreensiva e expressiva. A aprendizagem musical propicia às crianças e jovens uma nova maneira de exteriorização dos sentimentos que entendemos ser como meio de inter-relação entre os sentimentos. Assim, pensarmos nas possíveis contribuições do saber artístico (Educação Musical, Educação Especial, Educação Inclusiva) na perspectiva da inclusão entre estudantes da escola de educação básica e estudantes com deficiência merece grande destaque e visibilidade na nossa sociedade.

\section{O dia a dia da pesquisa, desafios e realizações}

O objeto de nossos estudos neste artigo, o processo e resultados da pesquisa "Práticas artísticas e musicais com crianças e jovens com deficiência: 
inclusão ou interação?", nos permite dizer que a realização de práticas artísticas com crianças e jovens com e sem deficiência possibilita a exteriorização de sentimentos e emoções, nas diferentes formas de apreensão e percepção da situação vivenciada. Em Vygotsky (2000) seria a inclusão gerada na convivência de crianças e jovens (Figura 1), ou seja, processos de resposta por "mediação", promovendo a interação. Convivência enquanto situação que protagoniza os processos de aprendizagem, desenvolvimento e interação.

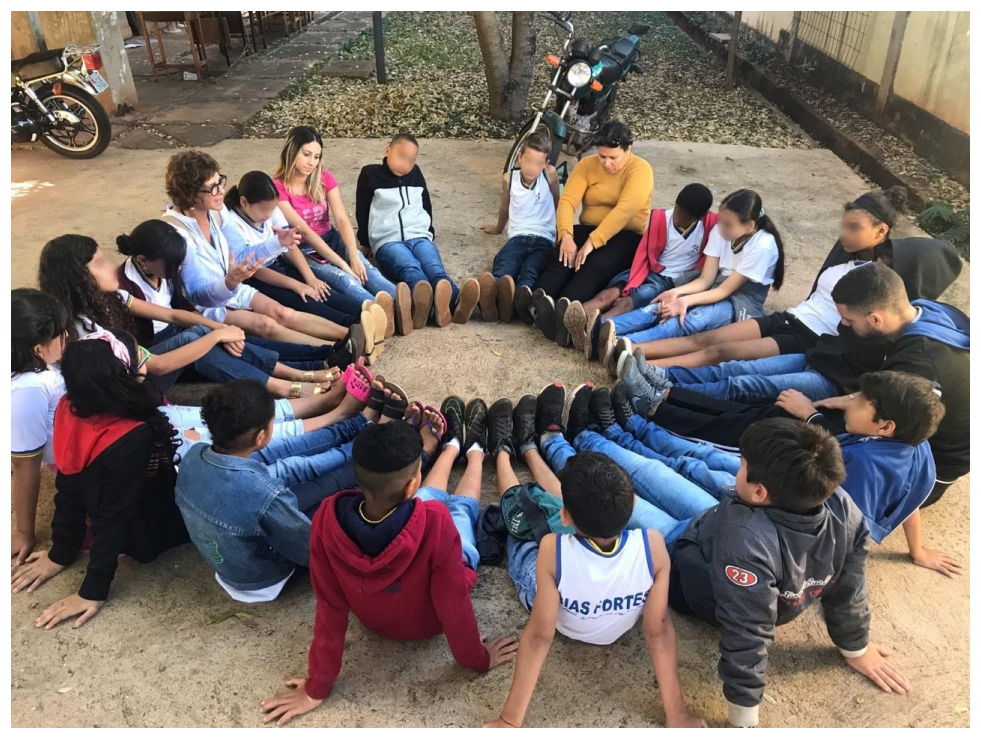

Figura 1. Participantes colaboradores conversando sobre as experiências vivenciadas no projeto. Fotografia das autoras, 2019.

Com aprovação do Comitê de ética, n. 14391019.0.0000.5525, e assinatura dos Termos de Consentimento Livre e Esclarecido, Termos de Anuência e Termos de Uso de Imagem, essa pesquisa foi realizada no período de abril de 2019 a janeiro de 2020, constando basicamente de dois momentos, metodologia de intervenção (levantamento e desenvolvimento) e metodologia de pesquisa (análise dos dados coletados). Levando-se em consideração os princípios pedagógicos do educador brasileiro Paulo Freire (2008), adotamos o termo "participantes colaboradores" para as crianças e jovens com e sem deficiência colaboradores nessa pesquisa, ao invés de estudantes.

A metodologia de intervenção foi desenvolvida de acordo com a pedagogia libertadora de Paulo Freire $(1967,2005)$, com base no diálogo e a partir das experiências e compreensões das pessoas envolvidas. As ações interventivas foram organizadas da seguinte forma: Investigação temática - negociação da intervenção com a escola sede e escolas parceiras, realização de roda de conversa com a comunidade participante (levantamento de gostos musicais, necessidades e preferências, vontades e expectativas); Tematização - apresentação dos dados resultantes da roda de conversa, escolha e decisão de repertório musical e literário, apresentação de cronograma de atividades das instituições - proponente 
(universidade), sede (APAE) e parceiras (conservatório e escola de educação básica), elaboração de arranjos musicais, roteiros, encenações dramáticas, jogos e brincadeiras; e Problematização - processo de construção-reconstrução do dia a dia das atividades pensadas e planejadas, ao longo dos encontros, além de apresentações e participação em concertos e oficinas, como de construção e manuseio de brinquedos. O arranjo musical foi criado para teclados, xilofones e metalofones, pratos de metal, caixa clara, pandeiro, Mbila ${ }^{1}$, clavas e voz, a partir de obras de compositores brasileiros.

Importante destacar que toda a construção da performance foi realizada ao longo de dezoito encontros, das 8 às 10 horas da manhã, com base no diálogo com os participantes colaboradores, pensando e discutindo interesses, vontades, individualidades, conhecimentos e aprendizados. Gonçalves Junior (2009, p. 705), estudioso da pedagogia dialógica de Freire, afirma: "O diálogo se faz necessário para entender posturas, posições, pontos de vista distintos, modos de perceber o mundo, e, de modo igualitário, compartilhar conhecimentos". Dessa forma, ao longo de todo o processo de intervenção, as educadoras também participavam das atividades propostas (Figura 2).

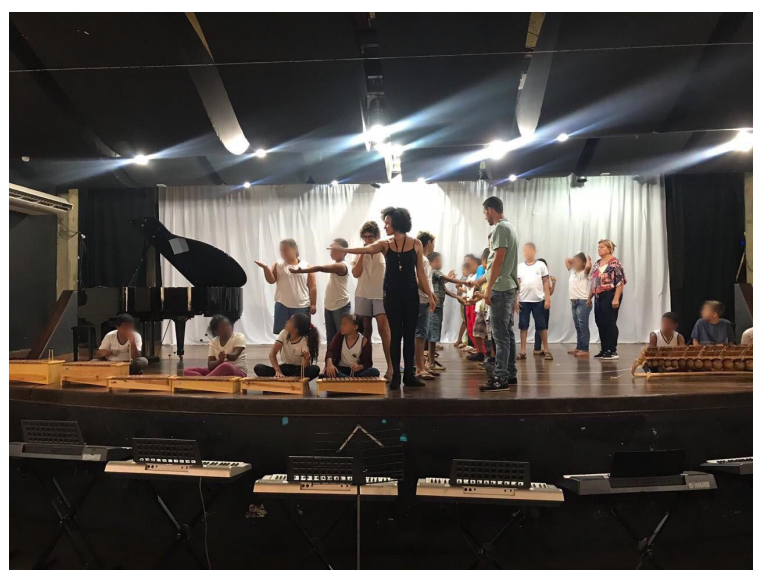

Figura 2. Participantes colaboradores (as) no palco na construção da performance.

Fotografia das autoras, 2019.

Já a metodologia de pesquisa constou de observação, registros fotográficos e audiovisuais e elaboração (escrita) dos diários de campo dos encontros realizados, os quais aconteciam semanalmente, envolvendo as instituições parceiras nesse projeto: a escola de educação básica, a APAE, a escola de música e a universidade. Segundo Bogdan e Biklen (1994, p.150), os diários de campo são compreendidos como "[...] o relato escrito daquilo que o investigador ouve, vê, experiencia e pensa no decurso da recolha e refletindo sobre os dados de um estudo qualitativo".

Após esse processo, realizamos nos meses de novembro e dezembro de 2019 a análise dos dados pautada na análise ideográfica e nomotética que, para

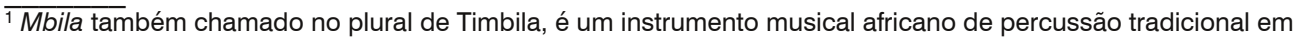
Moçambique.
} 
Gonçalves Júnior (2008), baseia-se na transcrição minuciosa e na íntegra dos discursos coletados nos diários de campo; identificação das unidades de significado; redução fenomenológica; organização das categorias; construção da matriz nomotética; construção dos resultados. A análise ideográfica e nomotética, segundo Machado (1994, p.41), contribui com pesquisas de natureza qualitativa "por possibilitarem que o tema seja circundado, em busca de compreender o fenômeno e não explicá-lo." Após a análise dos dados coletados, foi realizada uma devolutiva à comunidade participante, em conformidade aos preceitos éticos da pesquisa e compromisso das pesquisadoras.

No momento da problematização, o dia a dia dos encontros, envolvendo diferentes pessoas e instituições de ensino, as dificuldades foram muitas. A princípio a segregação das pessoas em grupos, divididos e organizados por escola (educação básica e APAE), até que, pouco a pouco, as pessoas, mas principalmente os participantes colaboradores (crianças e jovens com e sem deficiência) foram realizando as atividades de forma coletiva, agrupadas em um grande e único grupo, como que em resposta à "mediação" da proposta de construção coletiva trazida pelas educadoras.

No entanto, entendemos que esse agrupamento de pessoas foi possibilitado na convivência em meio à realização de práticas artísticas, situação que implicava a participação e envolvimento de todas as pessoas, fosse nas cirandas, na experimentação e instrumentação musical coletiva, na formação das rodas e/ou fileiras, enfim, na realização da performance. Práticas artísticas enquanto possibilidade de desenvolvimento cognitivo, emocional, afetivo e social entre essas crianças e jovens com e sem deficiência, entre tocar xilofones, metalofones (Figura 3), Mbila (Figura 4), cantar e dançar, encenar e dramatizar, manifestaram-se como modos de ser de cada pessoa envolvida (Figura 4).
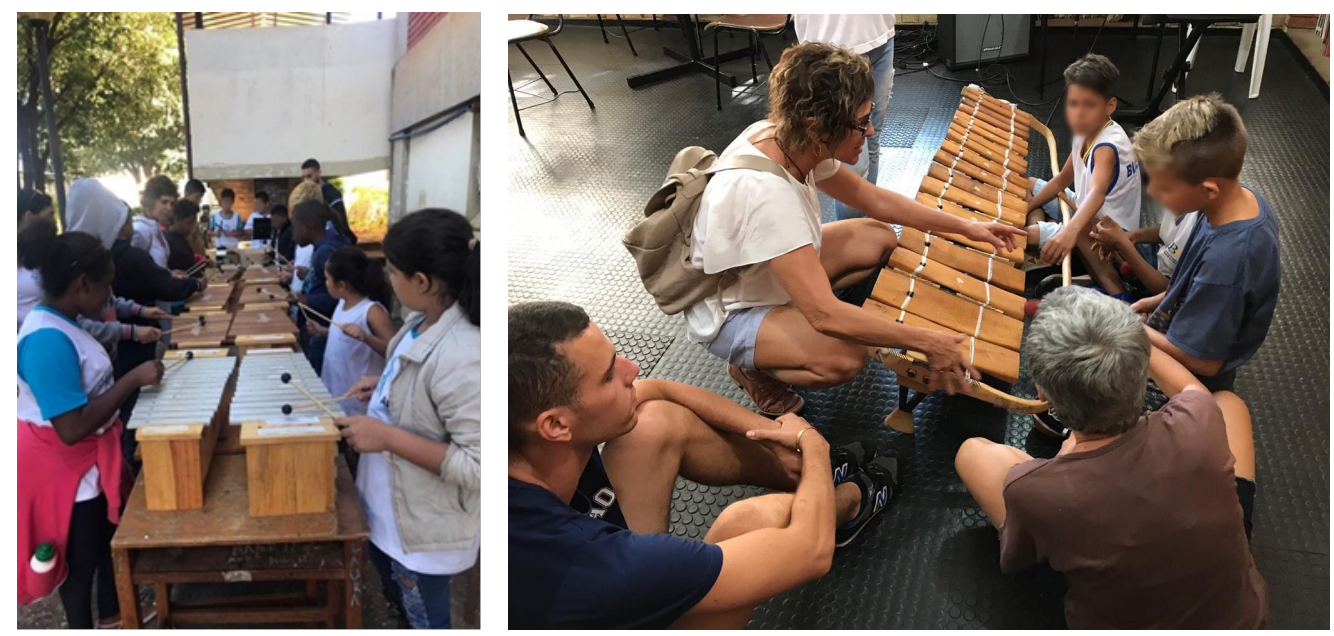

Figura 3. Participantes colaboradores (as) tocando xilofones e metalofones. Fotografia das autoras, 2019.

Figura 4. Participantes colaboradores (as) conhecendo o som do instrumento Mbila.

Fotografia das autoras, 2019. 
Tais observações corroboram com o conceito de Vygotsky (1999), de que a educação para pessoas que possuem déficits relacionados aos sentidos, como cegos e surdos por exemplo, não deveria ser orientada pelas deficiências, mas sim por outros potenciais existentes nessas pessoas, como um treinamento de outras capacidades. Daí o reforço do autor, de que primeiramente se deve educar a criança e não a criança deficiente, pois dessa forma atenta-se a outros potenciais, excluindo a ideia de que a deficiência limita a criança/jovem como um todo, fazendo com que ela não fique à mercê de suas limitações, mas sim ser estimulada em outros âmbitos.

Nessa pesquisa, ao longo dos encontros, as limitações físicas e/ou intelectuais dos participantes colaboradores não eram parâmetros para a participação. Todos podiam, e as afinidades entre pessoas foram se estabelecendo ao longo da convivência, como modos de interação, princípio dos processos de inclusão. Para Vygotsky (1998), a interação social é o modus operandi do desenvolvimento infanto-juvenil.

Nesse sentido, Góes (2002) observa que, a educação de pessoas com deficiência deve abranger os estímulos das funções psicológicas cognitivas. Não basta estimular a percepção relacionada ao olfato, paladar, visão, audição, tato, movimento, mas trabalhar além das limitações e não a partir dessas, trabalhar com possibilidades e não limitações. Crianças e jovens, inseridas em contextos em que prevalecem práticas artísticas, são estimuladas cognitivamente e perceptivamente, e o convívio direto entre pessoas com e sem deficiência promove aprendizados associados aos potenciais e não aos déficits.

Em meio a essa convivência, confirmamos os entendimentos de Candau (2008) e Freire (2008), de que é na interculturalidade, entendida como a convivência de pessoas de diferentes culturas, mais do que uma identificação cultural e identitária, mas no exercício assegurado de direito ao livre arbítrio, escolha e decisão, que se tem a possibilidade de interagir de modo criativo e dialógico. Por isso a realização de crianças e jovens com e sem deficiência em um mesmo propósito, da construção de uma performance, levando em consideração a liberdade de escolha, as diferentes formas de pensar e agir, as limitações físicas e mentais e os diferentes contextos sociais e culturais de cada uma delas, gerando novas aprendizagens e por conseguinte contribuindo com os processos de inclusão.

"Com-vivendo", deixando-se penetrar, aproximando-se de alguém ou de algo, situação que requer entrega, respeito, método, rigor, e necessariamente o espírito de cooperação, co-laboração em Freire (2005, p.156), característica de toda ação onde predomina o diálogo entre as pessoas, as quais se encontram para a “[...] 'pronúncia' do mundo, [...] uma condição fundamental para a sua real humanização". O fundamento da convivência humanizadora e transformadora é saber lidar com as individualidades, assumidas na coletividade.

Aquele que souber bem conviver, conviver verdadeiramente com essas liberdades em comunhão, é pessoa de autoridade, capaz de agir e poder transformar, assim: "Somente na medida em que os produtos que resultam da atividade do ser 'não pertençam a seus corpos físicos', ainda que recebam o seu selo, darão surgimento à dimensão significativa do contexto que, assim, se faz 
mundo" (FREIRE, 2005, p. 106). E nessa pesquisa, entendemos o quanto podem crianças e jovens com e sem deficiência dar sentido às suas realizações justamente na convivência em meio às práticas artísticas.

Para Vygotsky (1998, p.65), "[...] a experiência do aluno, o estabelecimento dos reflexos condicionados é determinado integralmente e sem qualquer reserva pelo meio social. Basta mudar o meio social para que mude incontinenti o comportamento do homem". Sendo a interação social o modus operandi do desenvolvimento infanto-juvenil, é imprescindível o convívio, no âmbito educacional, não só entre professores e alunos, mas também entre os estudantes, de forma coletiva, a partir das habilidades, potencialidades e reflexos individuais.

A interação se dá pela capacidade do ser humano em estabelecer comportamentos interpessoais e intrapessoal. E é por meio de práticas artísticas realizadas com crianças com e sem deficiência que elas se mostram potentes na promoção da interação social, justamente pela necessidade que tem todo ser humano de criar, ter novas ideias, construir novas capacidades, rompendo, assim, com os próprios limites e inaugurando outras possibilidades de ser, o "ser mais" em Freire (2005).

Por isso a necessidade de compartilhar experiências, conhecimentos, expectativas, interagir em busca de verdadeiramente incluir. É imprescindível questionar, já que o fazer artístico, como fenômeno multidimensional (dimensões culturais, afetivas, sociais, estruturais), extrapola todas as questões, além dos tantos fatores aos quais as pessoas estão expostas.

\section{Últimas palavras}

Compartilhamos com Vygotsky (1998), de que o modus operandi do desenvolvimento de crianças e jovens é a interação social, como possibilidade de surgimento de novos comportamentos interpessoais e intrapessoais. $\mathrm{Na}$ coletividade, habilidades são desenvolvidas, as pessoas se expressam e interagem. Da convivência proveitosa e produtiva, aqui particularmente de crianças e jovens com e sem deficiência, o processo de construção-reconstrução de performance aconteceu, tornou-se uma realidade.

A prática artística em seus diversos contextos pode, assim como ocorreu nesse projeto de pesquisa, "Práticas artísticas e musicais com crianças e jovens com deficiência: inclusão ou interação?", promover a convivência necessária para a efetivação dos processos de inclusão. A liberdade de escolha e o processo de construção-reconstrução de performance possibilitaram de forma prática o exercício da arte nos contextos cênicos, musicais e literários, levando em consideração que durante todo o processo os participantes colaboradores possuíam o livre arbítrio para permanecer ou não nas atividades do projeto, a aprender novas formas e manifestações de diferentes culturas, adquirir novos conhecimentos e habilidades, projetar-se na coletividade, ser em meio aos outros, ser mais!

A realização e desenvolvimento de práticas artísticas com pessoas com ou sem deficiência são capazes de potencializar habilidades, conhecimentos, percepções de mundo, abrangendo não só o desenvolvimento da exteriorização dos sentimentos e emoções, como também a capacidade interpessoal e 
intrapessoal das crianças e jovens envolvidos no processo, o que consideramos imprescindível para a formação cognitiva, psicológica e social das futuras gerações.

Tais práticas podem favorecer processos de inclusão e a arte, em seus diferentes contextos, além de possibilitar um ambiente de experimentação de sons, cores, sentimentos e emoções, pode gerar novos modos de realização. Os processos educativos decorrentes das práticas realizadas foram revelados na atuação de cada pessoa no momento da performance. Não se trata de falar do fazer, mas do fazer em si, como forma de expressão e manifestação de cada um, de um jeito muito próprio e particular.

Até mesmo os pais e familiares e pessoas responsáveis pelas crianças e jovens participantes nesse projeto confirmaram diferenças comportamentais positivas no processo de desenvolvimento intrapessoal e interpessoal, fossem nas famílias e/ou nas escolas sede. Vejamos a fala da mãe de um participante colaborador de 11 anos com de Síndrome de Down: "Eu achei ótimo, o meu filho não estava interagindo com as pessoas, ele era muito na dele, agora ele está mais extrovertido, tá aprendendo mais na escola."

No entanto, entendemos que são muitos os desafios. O dia a dia do projeto mostrou-se uma realidade a ser enfrentada, que demanda equipe multiprofissional, de pessoas imbuídas de compromisso e forte espírito de colaboração, além de sensibilidade, experiência e conhecimentos considerados adequados para trabalhos dessa natureza.

Assim, em face dos resultados, esperamos que esse artigo suscite reflexões acerca das tantas possibilidades de realização de práticas artísticas na promoção de processos de inclusão, de desenvolvimento cognitivo e aprendizagens de crianças e jovens com e sem deficiência. Práticas como essa podem se transformar em avanços epistemológicos, ressignificando o sentido da vida, promovendo a inclusão e sinalizando que a Educação é direito de todos, como forma potente de humanização, tão carente nos dias de hoje.

\section{Referências}

BOGDAN, Robert; BIKLEN, Sari. Investigação qualitativa em educação: uma introdução à teoria e aos métodos. Porto: Porto, 1994. 183 p.

CANDAU, Vera Maria. Direitos Humanos, educação e interculturalidade: as tensões entre igualdade e diferença. Revista brasileira de educação. v. 13, n. 37, p. 45-56, 2008. Disponível em: http://www.scielo.br/pdf/rbedu/v13n37/05.pdf. Acesso em: 7 de agosto 2020.

FREIRE, Paulo. Pedagogia da esperança: um reencontro com a pedagogia do oprimido. 15 ed. Rio de Janeiro: Paz e Terra, 2008. $336 \mathrm{p}$.

FREIRE, Paulo. Pedagogia do oprimido. Rio de Janeiro: Paz e Terra, 2005. 213 p.

GÓES, Maria Cecília Rafael. Relações entre desenvolvimento humano, deficiência e educação: contribuições da abordagem histórico-cultural. In: OLIVEIRA, Marta Kohl; SOUZA, Denise Trento R.; 
REGO, Tereza Cristina. (Org.). Psicologia, educação e as temáticas da vida contemporânea. São Paulo: Moderna, p. 95-114, 269-287, 2002.

GONÇALVES JUNIOR, L. Lazer e trabalho: a perspectiva dos líderes das centrais sindicais do Brasil e de Portugal em tempos de globalização. In: GONÇALVES JUNIOR, L. (Org.). Interfaces do lazer: educação, trabalho e urbanização. São Paulo: Casa do Novo Autor, p. 54-108, 2008.

LIMA, Marcelo Guimarães. "A psicologia da arte e os fundamentos da teoria histórico-cultural do desenvolvimento humano". Interações, vol. 5. Universidade São Marcos São Paulo, Brasil, 2000, p. 7381. Disponível em: https://www.redalyc.org/pdf/354/35450906.pdf Acesso: 06 de abril 2021.

PAPALIA, Diane E.; FELDMAN, Ruth Duskin. Desenvolvimento humano. 12 ed. Porto Alegre: AMGH, 2013. 800 p.

PEDERIVA, Patrícia Lima Martins; TRISTÃO, Rosana Maria. Música e cognição. Ciências e cognição, Rio de Janeiro, v. 9, p. 83-90, 2006. Disponível em:

http://www.cienciasecognicao.org/revista/index.php/cec/article/view/601/383. Acesso em: 20 de março 2021.

VYGOTSKY, Lev Semyonovich. A formação da mente: o desenvolvimento dos processos psicológicos superiores. Cole, Michael (Org.). 6 ed. São Paulo: Martins Fontes, 1998.191 p.

VYGOTSKY, Lev Semyonovich. A construção do pensamento e da linguagem. São Paulo: Martins Fontes, 2000. 496 p.

VYGOTSKY, Lev Semyonovich. Psicologia da arte. Trad. Paulo Bezerra. São Paulo: Martins Fontes, 1999. $377 \mathrm{p}$.

Recebido em 10/05/2021 - Aprovado em 21/09/2021

Como citar:

BATISTA, S. L.; MARTINS, D. A. de F.; ROCHA, P. S. Processos de inclusão de crianças e jovens com e sem deficiência em práticas artísticas. ouvirOUver, v.17, n.2. p. 321-330. jul./dez. 2021. https://doi.org/10.14393/OUV-v17n2a2021-60934

A revista ouvirOUver está licenciada com uma Licença Creative Commons Atribuição-NãoComercial 4.0 Internacional. 